\title{
Precambrian Basement Architecture and Lineaments Mapping of Ado-Ekiti Region Using Aeromagnetic Dataset
}

\author{
Cyril C. Okpoli and Michael A. Oladunjoye \\ Department of Earth Sciences, Faculty of Science, Adekunle Ajasin University, PMB 1, Akungba- \\ Akoko, Ondo State, Nigeria \\ Department of Geology, University of Ibadan, Ibadan, Nigeria \\ Email: cyril.okpoli@aaua.edu,ng; okpolicyril@gmail.com
}

\begin{abstract}
Aeromagnetic dataset over Ado-Ekiti Southwest (sheet 244) was processed to interpret the geology structure and estimate the depth to bedrock of magnetic sources as well as to deduce the basement architecture and their trends.

Aeromagnetic dataset were collected, filtered, inverted, and enhanced using appropriate software packages and subsequently employed to generate a model of the subsurface basement topography. The data processing steps involved were Butterworth filtering, reduction to the equator, analytic signal, upward continuation, Tilt angle derivative, Average power spectrum and Euler/Werner deconvolution.

The result shows that magnetic intensity from Butterwort ranges from -173.3 to $150.8 \mathrm{nT}$; Reduction to the pole varies from -213.1 to $314.1 \mathrm{nT}$; upward continuation at $100 \mathrm{~m}$ ranges from 156.1 to $142.4 \mathrm{nT}$ and analytical signal varies from 0.0 to $0.4 \mathrm{nT}$. The magnetic intensity distribution was found to depend on the size, depth of burial, and the thickness of low susceptibility superficial material overlying the magnetite rich crystalline rocks. Tilt angle derivative disclose the presence of fold, shearing, contacts, lineaments with its orientations while the 3D Euler deconvolution $>2000$ and dike model fits the Werner function. The average radial power analysis delineated shallow sources ranging from $0.34 \mathrm{~km}-0.49 \mathrm{~km}$ and deeper sources ranging from $0.45-1.25 \mathrm{~km}$. Pseudogravity result is $0.103 \mathrm{~g} / \mathrm{cc}$ which trends in NE-SW direction. The lineaments directions are in NE-SW, NW-SE and E-W directions which are Pan-African, Kibaran and Liberian Orogenies that occurred in the region.

Modeled maps of upward continuation, analytical signal, tilt derivative, pseudo gravity average power spectrum and 3D Euler /Werner deconvolution revealed the basement architecture including structural lineaments with its orientations and the depth to the magnetic sources of the study area.
\end{abstract}

Keywords: Aeromagnetic, 3D Euler/Werner deconvolution, pseudogravity, Ado-Ekiti, derivatives, basement architecture.

\section{Introduction}

High-resolution aeromagnetic data were recently collected in an Ado- Ekiti area and its surrounding towns to improve the regional geologic understanding of the subsurface geology (Reeves, 1985; Grant, 1985). Qualitative and quantitative analyses of the data were integrated to obtain a preliminary interpretation. The primary sources of aeromagnetic anomalies are interpreted as magnetite and intrusive with dominantly reversed-polarity remanent magnetization, weakly to moderately magnetic Precambrian crystalline basement, and magnetic Tertiary intrusions.

High resolution aeromagnetic surveys, in particular terms, map the magnetite in the rocks beneath the aircraft. Aeromagentic surveys are comprehensively used as reconnaissance tools and there has been a growing recognition of their value for appraising prospective areas by virtue of the unique information they provide. Highlights of the function of aeromagnetic surveys are: identification and interpretation of faulting, shearing, and fracturing not only as potential hosts for a variety of minerals, but also an indirect guide to epigenetic, stress related mineralization in the surrounding rocks (Reeves, 2005) Aeromagnetic survey used in direct detection of deposit of certain rocks rich in iron ores. Identification and delineation of post-tectonic intrusive: typical of such targets are zoned Syenite or Carbonatite 
complexes, kimberlites, tin-bearing granites, and mafic intrusions. Aeromagnetic survey is applied in the investigation of volcano-sedimentary belts under sand or other recent cover, or in strongly metamorphosed terrains when recent lithological units are otherwise unknown (Dobrin 1960). In prospecting for oil, aeromagnetic data can give information from which one can determine depths to basement rocks and thus locate and define the extent of sedimentary basins. Sedimentary rocks however exert such a small magnetic effect compared with igneous rocks that virtually all variations in magnetic intensity measurable at the surface result from topographic or lithologic changes associated with the basement or from igneous intrusions (Dobrin and Savit, 1988; Reeves, 2005). In other areas, the magnetic method has evolved from its sole use for mapping basement structures to include a wide range of new applications, such as water resource assessment (Smith and Pratt, 2003; Blakely, 1995), environmental contamination issues (Smith and Pratt, 2003), geothermal resources (Silva et al., 2003), volcano related landslide hazards (Finn et al., 2001), archeological mapping (Tsokas and Papazachos, 1992).

Other objectives of magnetic surveys are direct detection of metallic ores, determination of lineaments, extents of architecture of magnetic bodies and interpretation in relation to geology. Mafic igneous rocks have the highest susceptibilities and sedimentary rocks the lowest. Within the same rock type, magnetic susceptibility may differ considerably. Sometimes high magnetic anomalies could accompany authigenic alterations in sedimentary rocks and cultural iron contamination, due to hydrocarbon migration (Kearey and Brooks, 2002; Aldana et al., 2003). Hence, ground and aeromagnetic dataset is primarily responsible for the unmasking character of the subsurface particularly in geological mapping and mineral prospecting in areas with finite outcrop (Porwal et al., 2006; Allek and Hamoudi, 2008; Schetselaar and Rhyan, 2009; Okpoli and Adedibu, 2016; Okpoli and Eyitoyo, 2016).

In this paper, Analytical signal, reduction to pole, derivatives, spectra and Euler deconvolution were used to analyze and interpret total magnetic field data in providing enhanced understanding of the structural architecture and geologic model. As such, the wide-ranging aim of this study is to use the high resolution aeromagnetic dataset to provide new insight on the structural architecture of the study area.

\section{Geology of the Study Area}

The study area is located between longitudes $5^{\circ} 00^{\prime} \mathrm{E}$ and $5^{\circ} 15^{\prime} \mathrm{E}$ and latitudes $7^{\circ} 30^{\prime} \mathrm{N}$ and $7^{\circ} 45^{\prime} \mathrm{N}$, covering an area of 1,471.5 square $\mathrm{km}$. Ado-Ekiti region is generally accessible and motorable, the availability of both tarred and untarred roads as well as footpaths provide good accessibility to the area and to the outcrops. The geology of Ado-Ekiti region belongs to the basement complex (igneous rock) rock of South Western Nigeria. Major lithological rock units are basically crystalline basement rocks. These include coarse grained charnokite, fine grained granite, medium grained-granite and porphyritic biotite-hornblende granite, with superficial deposit of clay and quartzite. Association of the fine-grained charnokite and the porphyritic biotite-hornblende granite suggest a common age (Omotoyinbo, 1994). Rocks from the Archean-Proterozoic terrain of Ado-Ekiti, south-western Nigeria comprise mainly of migmatite, granite-gneiss, quartzite, granite (porpyritic and fine-medium grained) and charnokite. AdoEkiti constitutes a miniature of the geology of southwestern Nigeria. Most of the rocks in south western Nigeria with the exception of the schistose rocks are found in Ado-Ekiti. Migmatite-quartzite complex are the oldest rocks into which other rocks (older granite, charnokite, aplite and quartz veins) got intruded. The charnokites and the older granites intruded into these host rocks during the Pan-African orogeny. Migmatite - gneiss covers over $60 \%$ of the study area (Fig.1) into which the other successions of rocks have intruded. Migmatite rock exposures occur as highly denuded hills of essentially fine textures. The rocks composed of a mafic portion are made up of biotite, hornblende and opaque minerals while the felsic portion is quartzo-feldspartic. The rocks display compositional variations indicated by closely spaced alternating bands of leucocratic minerals (quartz and feldspars) and melanocratic minerals indicated by the preponderance of biotite minerals. The quartzite in the study area exhibits white to gray colour due to varied iron oxide in the rock. A few good massive quartzite outcrops rising up to 100 metres above the surrounding terrain occur around the south western part of the study area. Quartzite is very resistant to chemical weathering and often forms ridges and resistant hilltops. The charnokitic rocks outcropped as oval or semi-circular hills of between five and ten meters $(10 \mathrm{~m})$ high with a lot of 
boulders at some outcrops. They are generally massive, dark greenish in colour with medium to coarse grained texture. The general trend of the intrusions is N-S. The dominant trend of the joints that occur on the rock is N-S. The charnokitic rock is the most abundant in the area. The charnokite ranges in colour from dark-green, to greenish-grey rock with milky quartz and greenish feldspar Oyawoye, 1972; Rahaman, 1976, 1981. The outstanding feature of the coarse grained variety of charnokite rock in AdoEkiti is that it is similar to those of Oyawoye (1972), described as "bauchite" around Bauchi Nigeria. Other occurrences are in form of small dykes or veins in other granitic rocks. The rock is generally even textured and homogenous with mineral aggregates mainly of biotite and feldspar phenocryst. The superficial deposits are clay, quartzite rumbles and fine sand $\left(\mathrm{SiO}_{2}\right)$. The clay is believed to have been formed from the weathering of feldspar mineral present in charnokitic rocks due to alteration of igneous rocks by hydrothermal process and the quartzite rumbles due to high degree of cyclic weathering. The charnokites in Ado-Ekiti fall within those that occur along the margins of Older Granites bodies especially the porphyritic granites. The other modes of occurrence comprising of charnokites that aligned in a NW-SE direction hardly outcropped in Ado-Ekiti but are found at Itapa, Ijelu, Oye and Ikole areas of Ekiti State. Megascopic examination with the aid of hand lens revealed the presence of quartz, alkali feldspar, plagioclase and biotite as major mineral in the charnokitic rocks of the study area. The Older Granites comprise of felsic and mafic minerals. The felsic minerals include quartz, orthoclase, plagioclase feldspar and muscovite while the mafic group comprise of the black coloured biotite and the dark green to black hornblende of the amphibole group. The granites are distinguishably unique in that it lacked foliation but with visible mineral components. In addition, the granites have porphyritic and finemedium grained texture with compact interlocking crystals. Some of the outcrops occur as well-rounded boulders devoid of any preferred orientation of component minerals. Generally, the porphyritic granite is light coloured and fairly weathered compared to the fine-medium grained variety Grant, 1978; Rahaman, 1988, Anifowose, 2004.

\section{Precambrian Basement Mapping Architecture}

Several works have been done in the Ado-EKiti region and similar areas. Such works include, Rahaman (1988), Odeyemi (1981), and Anifowose (2004), who have given account of the geology of this area. Oyawoye (1964), Rahaman (1988), and Odeyemi (1981) note that the rocks in this region illustrate evidence of polyphase deformation with the plutonic episode of the Pan African event being the most invasive. Rahaman (1988) notes that the south western basement complex of Nigeria lies within the rest of the Precambrian rocks in Nigeria, he grouped the rocks in this area as migmatite - gneiss complex comprising largely of sedimentary series with associated minor igneous rock intrusions which have been altered by metamorphic, migmatitic and granitic processes. Odeyemi (1981) suggests that almost all the foliation exhibited by rocks of southwestern Nigeria excluding the intrusives are tectonic in origin, because pre-existing primary structures have been destroyed by-subsequent deformation. Anifowose (2004) also observes that joints ranging from minor to major ones are found in all the rock types, some of which are filled with quartz, feldspars or a combination of both which lie generally in the NE-SW direction, while the south western basement complex of Nigeria has been affected by two phases of deformation namely D1, D2, the first phase (D1) produced tight to isoclinals folds while the second phase (D2) is characterized by more open folds of variable style and large vertical NNE-SSW trending fault. Okonkwo (1992) gives evidence that within the basement complex, tectonic deformation has completely destroyed primary structures except in a few places where they survived deformation.

\section{Materials and Methods}

\subsection{Aeromagnetic Data and Analysis}

\subsubsection{Data Acquisition}




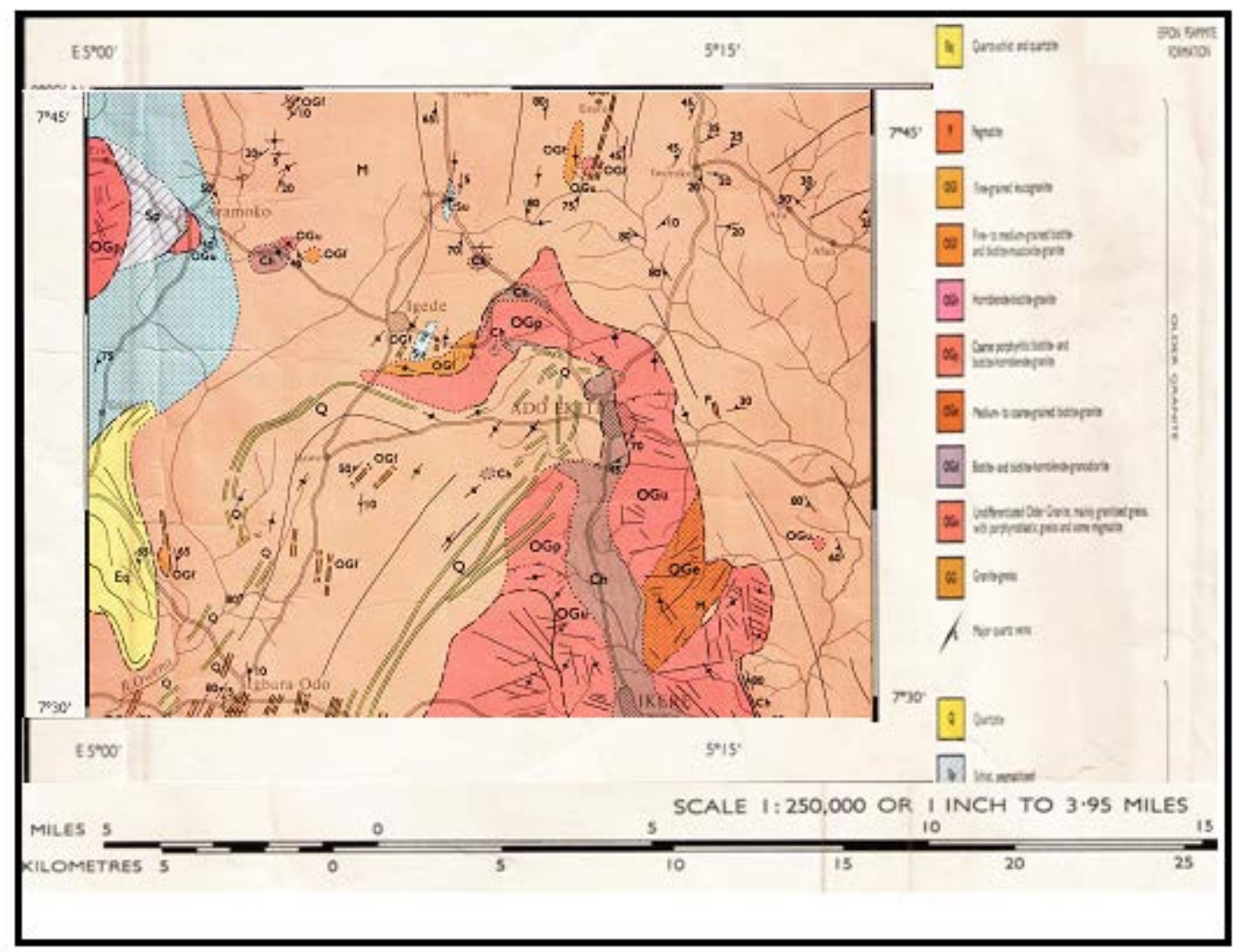

Figure 1. Geological map of the study area (Source: NGSA)

With the nationwide mandate of acquisition of high resolution airborne geophysical survey aimed at assisting and promoting mineral exploration in Nigeria, aeromagnetic data was acquired between 2003 and 2009 by Fugro Airborne Survey Limited for the Nigerian Geological Survey Agency (NGSA) (MMSD, 2010). The data was acquired systematically by dividing the country into geological blocks with divergent measurement parameters for each block with the eventual production of an aeromagnetic map for the whole country (Figs. 2 and 3).

The following equipment specifications were used-Scintrex CS3 Cesium Vapor magnetometer, Data Acquisition System FASDAS, Magnetic Counter FASDAS, Radar Altimeter KING KR405/KING KR405B, Barometric Altimeter ENVIRO BARO/DIGIQUARTZ. Scintrex CS3 optically pumped Cesium Vapor magnetometer was used for scalar measurement of the Earth's magnetic field. It can be used in a variety of applications such as airborne, satellite, ground magnetometry, or gradiometry. It is highly sensitive and measures in the range of pT $(1 \mathrm{pT}=0.001 \mathrm{nT})$ in a measuring bandwidth of $1 \mathrm{~Hz}$ and this sensitivity does not deteriorate as the measured ambient field decreases. It measures between 15,000 nT and 100,000 nT. The sensor head has an electrode-less discharge lamp (containing cesium vapor) and absorption cell. Electrical heaters bring the lamp and the cell to optimum operating temperatures with controlling and driving circuits located in the electronics console. Heating currents are supplied to the sensor head through the interconnecting cable.

Ado-Ekiti and its environs designated as Sheet 244; are part of Block B and are surveyed in Phase 1 of the project. The survey was carried out by fixed wing (Cessna) caravan -208B ZS-FSA, 208 ZSMSJ,406 ZS-SSC aircrafts covering a total of 235,000 line kilometers with a flight spacing of 200 meters and a terrain clearance of 80 meters. The flight direction was NW-SE with tie-line spacing of 200 meters and tie-line direction of NE-SW.

A recording interval of 0.1 secs and a grid mesh size of 50 meters were applied in the World Geodetic System of 1984 (WGS84) within UTM Zone 36S,central median 33 ${ }^{\circ} \mathrm{C}$ East, Central scaling factor 0.999 6and with the Spheroid Clark 1880/Arc 1960 coordinate system. 


\subsection{Data Processing}

The data is that of total field and is in a gridded form as a total magnetic intensity (TMI) map (Fig. 4). This method fits minimum curvature curves (which is the smoothest possible surface that would fit the given data values) to data point using method described by Briggs (1974).

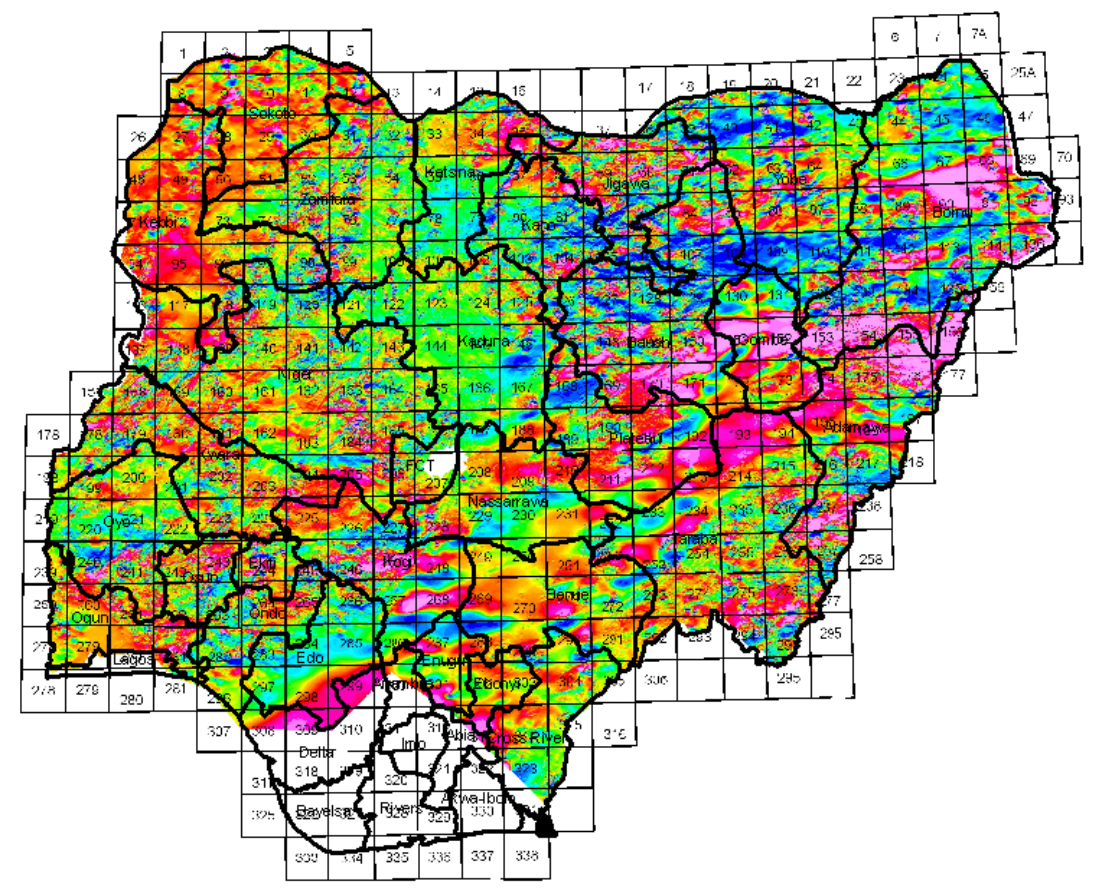

Figure 2. Nigeria Magnetic Index map (Source: NGSA)

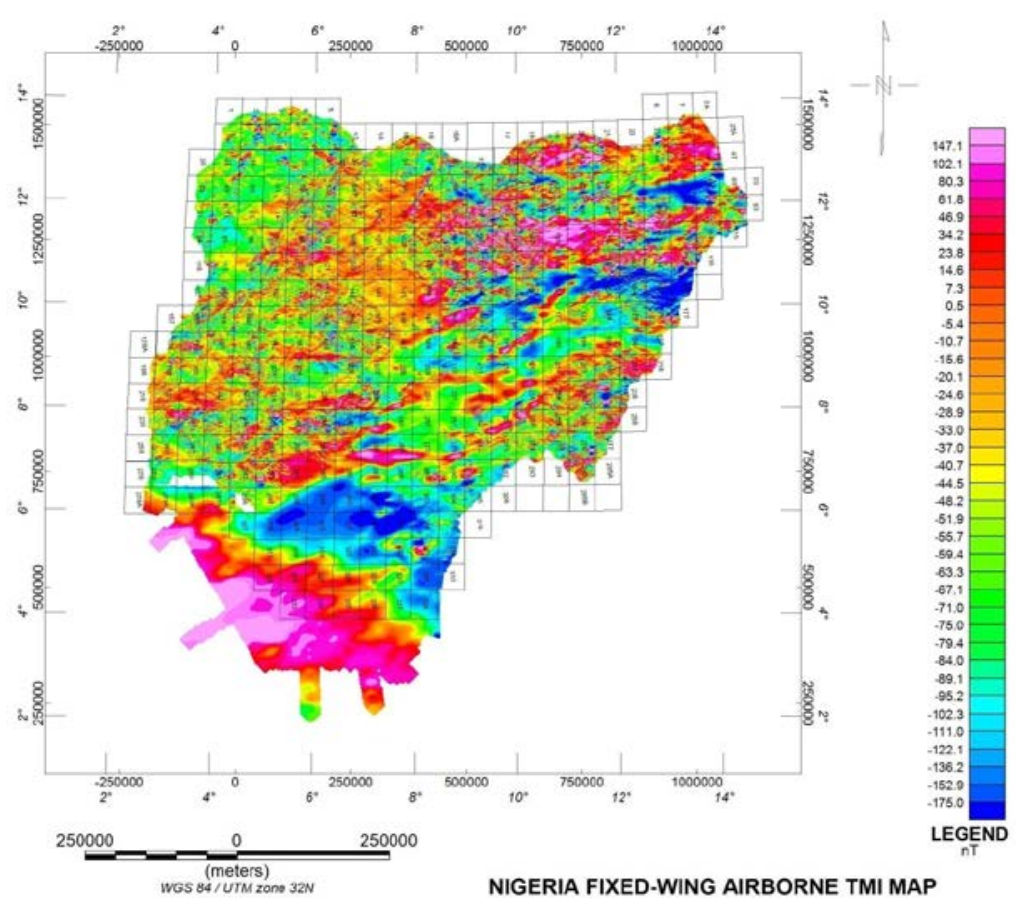

Figure 3. Nigeria Fixed- wing Airborne TMI Map (Superimposed federal Survey half Degree Sheets) Source: NGSA. 


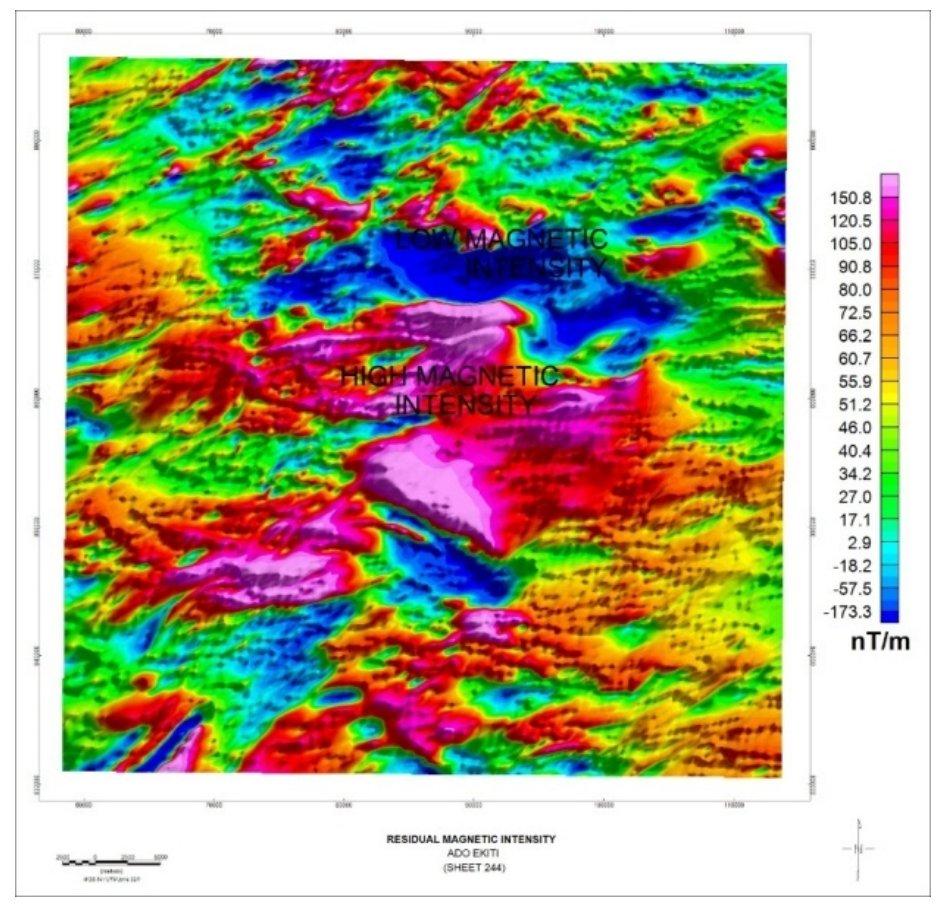

Figure 4. Colour shaded Residual magnetic intensity map of Ado-Ekiti sheet 244 Southwest and environs

Enhancement techniques in potential field methods are: Fourier filtering techniques, spectral analysis, Euler and Werner deconvolution, tilt, horizontal and vertical derivatives, and analytical signal value added products that may contribute to the geological interpretation of magnetic dataset by way of map/ better images produced. Geophysical Fourier filtering techniques: upward and downward continuation, vertical derivative are based on physics of potential field (gravity and magnetic dataset) while mathematical fourier filtering are: horizontal derivative, low and high pass filters such as Butterworth, Gaussian and simple low-pass/high-pass cut-off filters e.g anti-alias filters applicable to any kind of dataset.

Enhancements of magnetic field data are processing operations designed to preferentially emphasize the expression of a selected magnetization at the expense of others. Airborne and ground geophysical data can be enhanced by a range of linear and non-linear filtering algorithms which selectively enhance the anomalies due to one group of geological sources relative to anomalies due to other groups of geological sources (Milligan and Gunn, 1997). Mathematical enhancement techniques are complemented by a range of imaging routines which can be specified to visually enhance the effects of selected geological sources. Fourier transforms are particularly useful in the transformation from the frequency domain to the wave number domain and also for the calculation of derivatives (Telford et al., 1990). Conversely, some enhancement operations distort the data, and care must be taken to ensure that enhanced data is not used inappropriately.

\section{Horizontal Derivative}

This process involves a phase transformation as well as an enhancement of high frequencies. The phase transformation generally has the result of producing anomaly peaks approximately located over the edges of wide bodies and the enhancement of the high frequencies sharpens these peaks to increase the definition of the body edges (Milligan \& Gunn, 1997).

\section{Vertical Derivatives}

Vertical derivative (or alternatively named - vertical gradient $\|$ ) filters preferentially amplify shortwavelength components of the field at the expense of longer wavelengths (Foss, 2011). Vertical derivative filters are generally applied to gridded data using FFT (Fast Fourier Transform) filters. Various vertical derivatives of the magnetic field can be computed by multiplying the amplitude spectra of the field by a factor of the form: 


$$
\frac{1}{n}\left[\left(u^{2}+v^{2}\right)^{\frac{1}{2}}\right]^{n}
$$

where $n$ is the order of the vertical derivative. The first vertical derivative (or vertical gradient) is physically equivalent to measuring the magnetic field simultaneously at two points vertically above each other, subtracting the data and dividing the result by the vertical spatial separation of the measurement points. The second vertical derivative is the vertical gradient of the first vertical derivative and so on. The formula for the frequency response of these operations shows that the process enhances high frequencies relative to low frequencies, and this property is the basis for the application of the derivative process which eliminates long-wavelength regional effects and resolves the effects of adjacent anomalies. First vertical derivative data have become almost a basic necessity in magnetic interpretation projects (Gunn et al., 1997).

\section{Vertical Continuation of the Field}

The amplitude of a magnetic field above a source varies with elevation as an exponential function of wavelength. This relationship can be readily exploited with FFT filters to re-compute the field at a higher elevation (upward continuation\|) or lower elevation (downward continuation (where $\mathrm{z}$ is positive downward) (Foss, 2011). A potential field measured on a given observation plane at a constant height can be recalculated as though the observations were made on a different plane, either at higher or lower elevation. As described by Gunn et al (1997), the process has a frequency response of $e^{-h}\left(u^{2}+v^{2}\right)^{1 / 2}$ (where $h$ is elevation). This means that upward continuation smooth out high-frequency anomalies relative to low-frequency anomalies. The process can be useful for suppressing the effects of shallow anomalies when detail on deeper anomalies is required. Downward continuation on the other hand sharpens the effects of shallow anomalies (enhances high frequencies) by bringing them closer to the plane of observation (Telford et al., 1990).

$$
F(x, y,-h)=\frac{h}{2 \pi} \iint \frac{F(x, y, 0) \delta x \delta y}{\left[\left(x-x^{\prime}\right)+\left(y-y^{\prime}\right)+h^{2}\right]}
$$

where $F(x, y,-h)=$ Total field at the point $P\left(x^{\prime}, y^{\prime},-h\right)$ above the surface of which $F(x, y, 0)$ is known as $h=$ elevation above the surface

\section{Reduction to the Pole}

Reduction to the pole (RTP) was a standard part of magnetic data processing method used for largescale mapping of aeromagnetic dataset of Ado-Ekiti. RTP operation transforms a magnetic anomaly caused by an arbitrary source into the anomaly that the same source would produce if it is located at the pole and magnetized by induction only. Reduction to pole eliminates the influence of magnetic latitude on the anomalies, which is significant for anomalies caused by crust. Reduction to the pole is the process of converting the magnetic field from magnetic latitude where the Earth's field is inclined, to the field at a magnetic pole, where the inducing field is vertical (Luo et al., 2010; Milligan \& Gunn, 1997; Li, 2008).

\section{Analytic Signal}

Analytical signal of TMI has much lower sensitivity to the inclination of the geomagnetic field than the original TMI data, and provides a means to analyze low latitude magnetic fields without the concerns of the RTP operator. Analytical signal is a popular gradient enhancement, which is related to magnetic fields by the derivatives. Roest et al (1992) showed that the amplitude of the analytic signal can be derived from the three orthogonal gradient of the total magnetic field using the expression:

$$
|A(x, y)|=\sqrt{\left(\left(\frac{\delta m^{2}}{\delta x}\right)+\left(\frac{\delta m^{2}}{\delta y}\right)+\left(\frac{\delta m^{2}}{\delta z}\right)\right)}
$$

where $A(x, y)$ is the amplitude of the analytical signal at $(x, y)$ and $\mathrm{m}$ is the observed magnetic anomaly at $(x, y)$.

While this function is not a measurable parameter, it is extremely interesting in the context of interpretation, as it is completely independent of the direction of magnetisation and the direction of the 
Earth's field (Milligan \& Gunn, 1997). This means that all bodies with the same geometry have the same analytic signal.

\section{Tilt Angle Derivative}

Since the amplitude of magnetic signature depends on magnetic field strength and to some extent the depth of magnetic sources, lower amplitude signature may be suppressed at the expense of higher amplitudes. For this reason, the edge-detection filters area normally applied for delineating linear features without necessarily diminishing the long-wavelength anomalies (Oruc \& Selim, 2011; Miller and Singh, 1994). The Tilt derivative filter, TDR (a very good edge-detection filter) brings out short wavelength and reveals the presence of magnetic lineaments. Verduzco et al (2004) showed in his work that tilt derivative filter also performs an automatic-gain-control (AGC) filter which tends to equalize the response from both weak and strong anomalies. Hence, the filter provides an effective way to trace out along striking anomalies (Cooper and Cowan, 2006).

\section{Results and Discussion}

Rocks of the study area showed different aeromagnetic responses that can be related to their lithology and tectonic activities that have resulted in the geological structures (e.g. folds, faults and fractures) in the area. The pink colours or characters in the presented figures (Figs. 5-16) are areas of high magnetic signature, whereas the blue characters represent areas of low magnetic signature.

\subsection{Residual Magnetic Intensity (RMI)}

The residual magnetic data was gridded with a $100 \mathrm{~m}$ grid space to show the spatial distribution of magnetic anomaly. The amplitude of a magnetic anomaly is directly proportional to magnetisation which depends on magnetic susceptibility of the rocks (Gunn et al., 1997). Residual magnetic intensity level in the study area ranges from -173.3 to $150.8 \mathrm{nT}$ with the mean value of $-0.067 \mathrm{nT}$. High magnetic values were observed in the central part of the study area which may be attributed to the presence of moderately high magnetic rocks (biotite-rich-granite and migmatite-gneiss). Fig. 5 shows some Negative magnetic values were observed in the area which may be due to the presence of low magnetic rocks (e.g schist and quartz) in the area, that are noted for low magnetic signatures (Telford et al, 1990). The residual magnetic field intensity data was gridded using the minimum curvature method (Fig. 5). To highlight the appearance of anomalies near surfaces, the colour-shade grid with illumination inclination of $45^{\circ}$ and declination at $45^{\circ}$ was applied. The total magnetic image showed the difference in locations of high and low magnetic intensities (Fig. 5) indicating that the study area is a basement terrain from the RMI image, other noticeable high (intermediate with amplitude (72.5-105.0 nT) and pockets of low magnetic susceptible body were observed at the north-western and north-eastern part of the RMI map in Fig. 5 .

\subsection{Reduction to Pole}

Both RMI (Fig.5) and the reduction to the pole RTP image (Fig. 6) display similar magnetic features, but in the RTP image the highs (pink colour) of the RMI are seen as lows (blue colour) though not in all cases. The RTP map shows more significant features such as structures and lithology in the magnetic signature than the residual magnetic intensity map. Some features such as the high magnetic signature (A,B,C) with amplitude range between 131.9 - $314.1 \mathrm{nT}$ indicate high and low magnetic signature at the Northwestern, and Northeastern part of the image.. Clear lithological boundaries are also observed in the image. These boundaries are observed from the sharp contrast in the magnetic signature on adjacent magnetic bodies. Some magnetic contrasts observed in Fig. 6 are interpreted as the lithological boundaries. Prominent is the contact (A and D, in Fig. 6) between the quartzite (delineated as displayed by a fairly sharp magnetic contrast). 

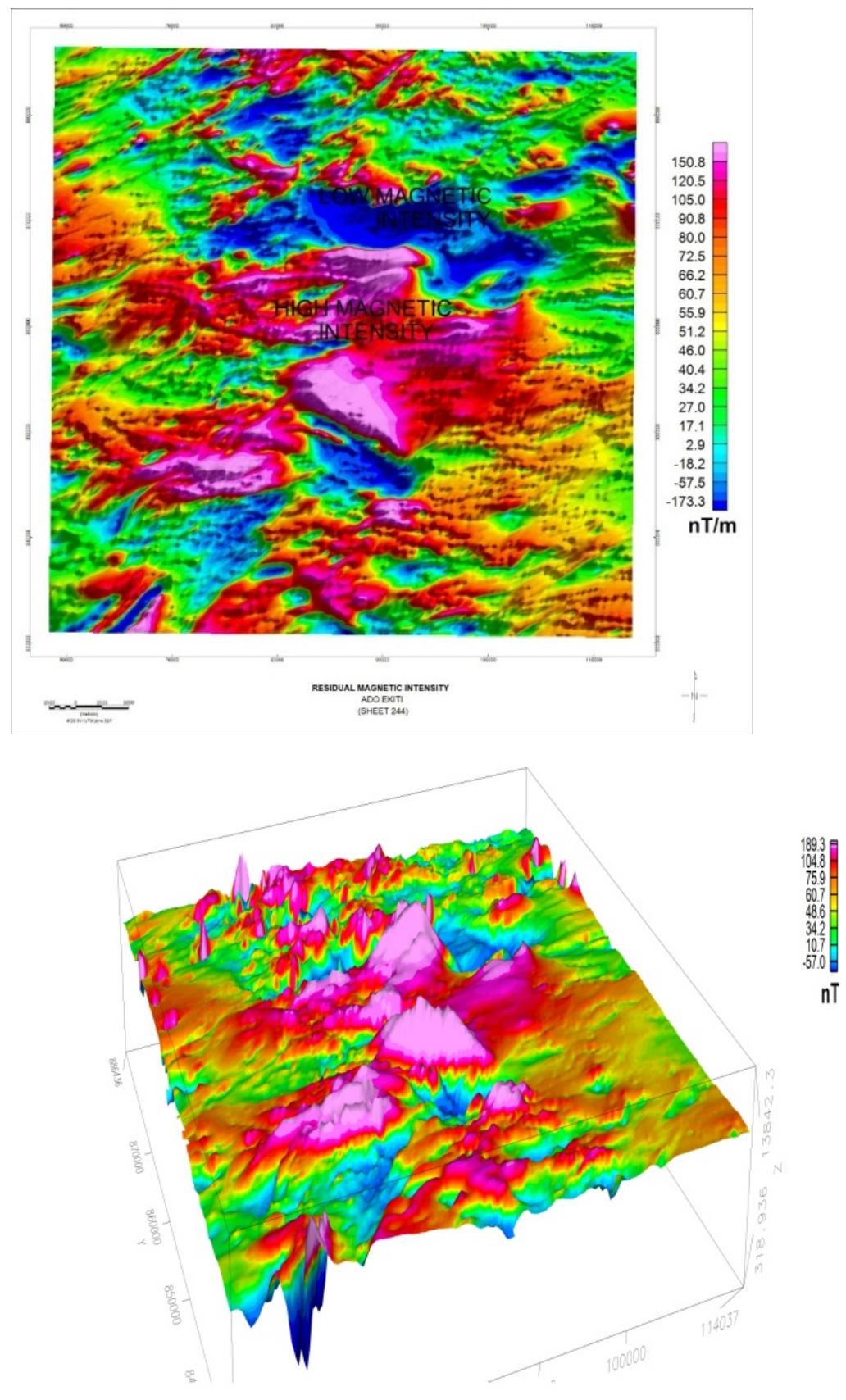

Figure 5. Residual magnetic intensity map and 3D view showing areas of high and low magnetic intensity.

\subsection{Analytical Signal}

The analytical signal map displays the magnetic zone with high intensity of $0.2 \mathrm{nT}-0.4 \mathrm{nT}$ (pink) from north to south and towards the west while regions with low magnetic intensities 0.00-0.01 nT (blue) can be seen in the southeast. Three major magnetic zones i.e. high magnetic anomalous zone are defined as $(\mathrm{AB})$, intermediate magnetic anomalous zone (AG), and low magnetic anomalous zone (AH) were delineated (Fig. 7). The high magnetic signatures at (AM) of the analytical map are the migmatite rocks which are found around the south to north part of the area trending in the direction of northeastsouthwest (Telford et. al., 1990). Lithological contacts portrayed by a sharp magnetic contrast from 
high to low were accentuated; prominent among them were the migmatite-quartzite contact (white line) and the granite-migmatite contact (yellow line). The granite is acidic, constituting minerals of low magnetic intensities such as quartz when compared to migmatite rocks, which dominates the area. Merging the enhanced tilt derivative map and the analytical signal map makes noticeable the regions in which faults and fractures have been filled with magnetic minerals (Ndougsa-Mbarga, 2011). These areas include: Igbara-Odo, Erijiyan, Ilawe-Ekiti Environment, and a very large anomaly lies beneath the Igbede Ekiti and Iyin - Ekiti. It can also be deduced from the analytic signal map that these near surface anomalies mainly cover the region occupied by the migmatite-gneiss complex rocks. In general, the analytical signal image (Fig. 7) revealed the different lithological units and geological structures in the area. The analytical signal map (Fig.7) is also useful in the location of edges of magnetic source bodies particularly where remanence and / or low magnetic latitude complicates interpretation (Thompson, 1982).

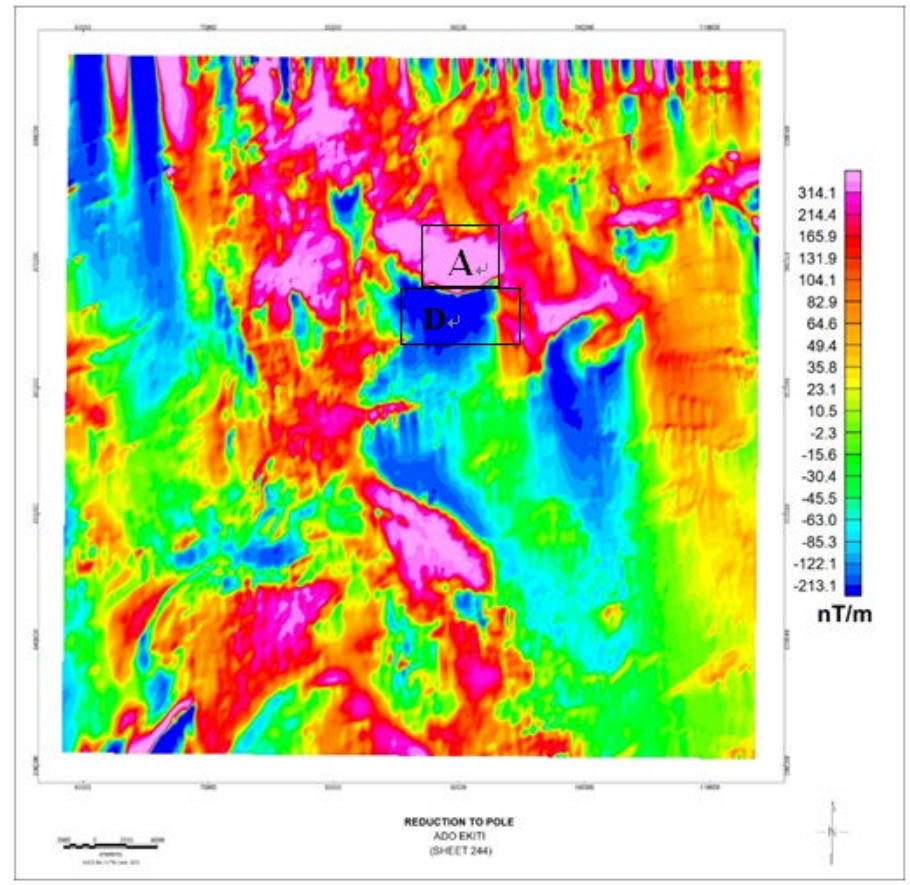

Figure 6. Reduction to the pole (RTP) image

\subsection{First Horizontal Derivative}

To observe the near surface source magnetic features that are associated with geological structures, the first horizontal derivative filter was applied to the RMI grid. The colour scale horizontal gradient images of the total magnetic intensity (Fig. 8) enhanced the image by showing major structural and lithological details which were not obvious on TMI image (Fig. 5). Geological structures were well delineated at NW-SE and NE-SW which might be considered as a fault or fracture

\subsection{Downward Continuation Filter}

Figure 9 shows the downward continuation of the RMI map. From the downward continuation map, it is seen that the boundaries of the different formations were not well demarcated and the features that are present are not well enhanced and the entire map is rough compared to the upward continuation. The downward continuation map enables the easy observation of short wavelength anomalies not seen in the original RMI Map. From this map structural interpretations were carried out through visual inspection, because of the small mineralized bodies in the study area. Eight of the short wavelength high amplitude anomalies A, B,C,D,E,F,G, and H (Fig. 9) have no similar trend (approximately East-West) 
with prominent anomalies B, C and D (110.7 nT - $165.0 \mathrm{nT})$. For instance F1 - F2 and F3 - F4 represents lineaments.
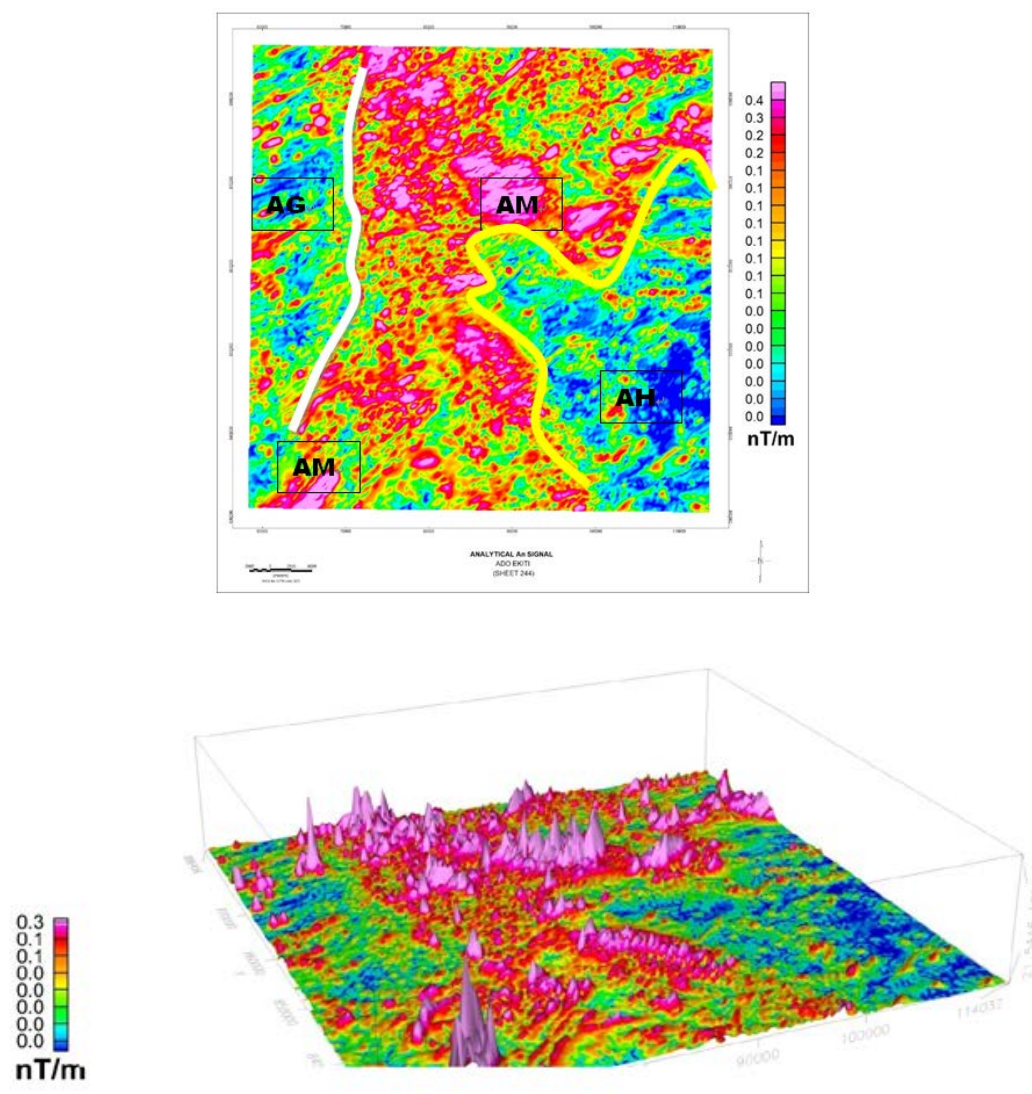

Figure 7. Analytic signal image of total magnetic intensity on $3 \mathrm{D}$ view.

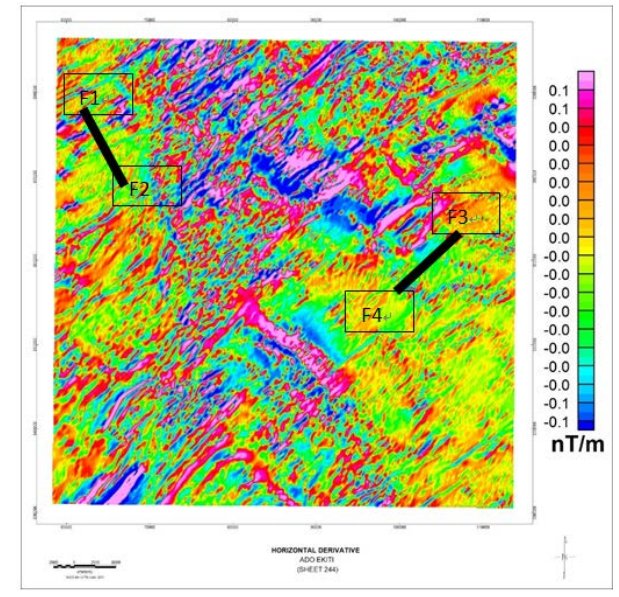

Figure 8. First Horizontal derivative map of the TMI grid.

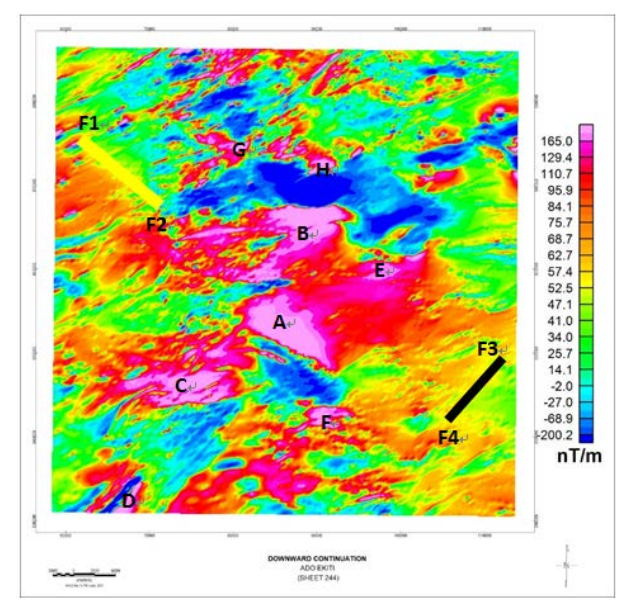

Figure 9. Downward continuation map of the TMI grid. 


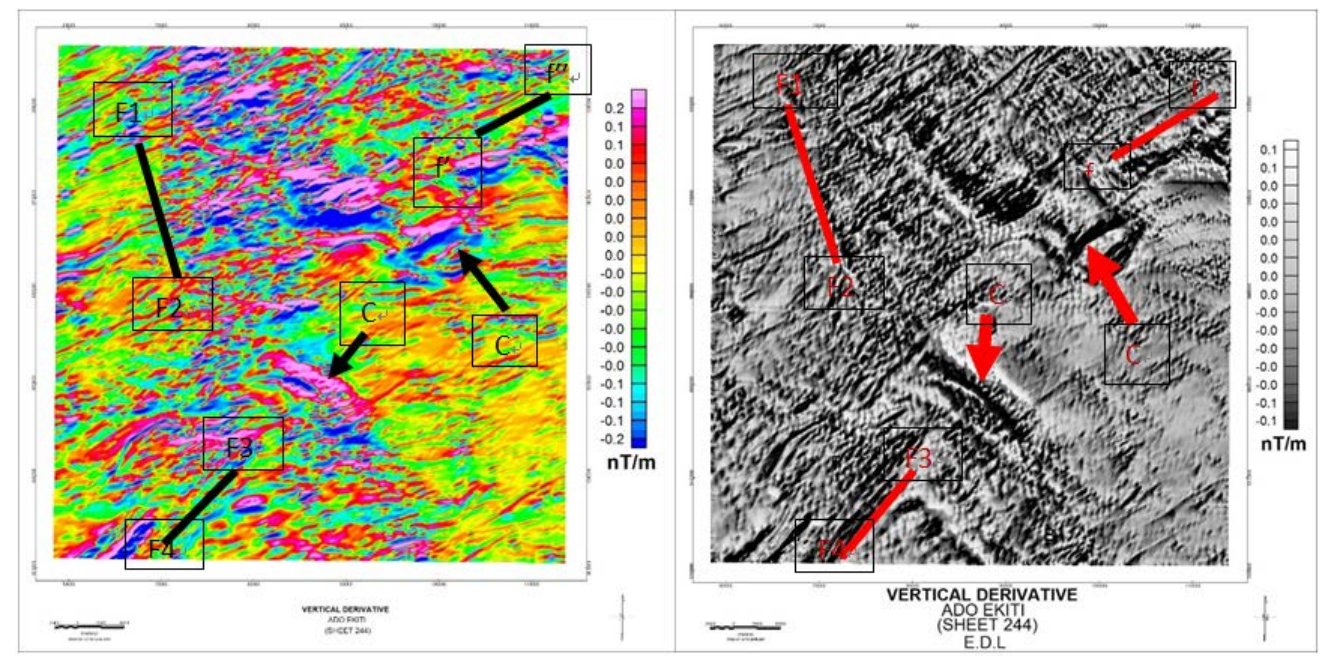

Figure 10. First vertical derivative map of the TMI grid. (a) colour shaded map (b) grey scale map

\subsection{Vertical Derivative}

A grey scale is applied to the first vertical derivative of the RMI. This helped in the identification of features such as folds (F1-F2, F3-F4), fault (f'-f"), contact (C) in the derivatives maps. Figure 10 is the first vertical derivative of the reduced magnetic intensity. The grey scale was very helpful as it helped to pinpoint these geological structures.

\subsection{Estimation of Basement Depth}

\subsubsection{Euler Deconvolution}

Euler solution was applied in determining the depth to the magnetic sources in the survey area by setting an appropriate Structural Index, SI (Fig. 11). The gridding interval enables recognition of any anomaly that is up to $75 \mathrm{~m}$ in wavelength, hence many solution points which sum up to 34,595 . Result with tightest cluster around recognized sources is likely to give the best solution and therefore accepted. Euler depth gave useful information about the subsurface architecture/topography of the basement complex. Solutions for Ado-Ekiti Southwest regions indicate relatively deep basement source, greater than $2000 \mathrm{~m}$ in depth bsl as seen underlying Ilawe Ekiti and progressively gets shallower northwards and southwards. Euler depths result ranged from $1 \mathrm{~m}$ to $2233.9 \mathrm{~m}$ overlap with rocks contacts while depth ranging between 0 and $132.2 \mathrm{~m}$ bsl which coincide to part of the study area where the basement rocks are overlain by clastic materials. The Euler depth below the datum are scattered all over the study area and are less conspicuous. Integrating the windowed Euler solution map with the proposed geologic map indicates that these magnetic sources align with lineaments and folds which play host to these dike bodies. Neighborhood such as Iyin-ekiti $(600-1000 \mathrm{~m})$, Ilawe-Ekiti (1500-2200 m), parts of Ogotun Forest Reserve $(250-750 \mathrm{~m})$, Igbara-Odo (0 to $100 \mathrm{~m}$ and 0 to $1500 \mathrm{~m}$ ) indicating negative and positive anomalies respectively, Erijiyan $(750-1500 \mathrm{~m})$ and Apata Hill $(250-1000 \mathrm{~m})$ all correlate to section of the study area underlain by lineaments and folds which host these sources. The Euler depth below the datum are scattered all over the study area and are less conspicuous.

\subsubsection{Power Spectrum}

Power Spectrum is a 2D function of the energy and wave number and can be used to identify average depth of source assemblages (Spector and Grant, 1970). Fig. 12 is the result of the computed radial power spectrum and depths to top of the magnetic sources around Ado-Ekiti Southwest. . The Figure shows that the depth to the top of the deeper magnetic source ranges from $0.45-1.25 \mathrm{~km}$ characterized by longer wavelength anomaly while most of the shallower sources ranges from $0.34 \mathrm{~km}-0.49 \mathrm{~km}$ characterized by short wavelength anomaly. The shallower sources probably depicted depths to Precambrian basement or near surface igneous intrusive rocks (such as migmatite complex and granite) 
with remnant magnetism. The deeper sources were characterized by high negative anomaly values having longer wavelength and depicted basic intrusive rock at depth or intruding dike at depth.

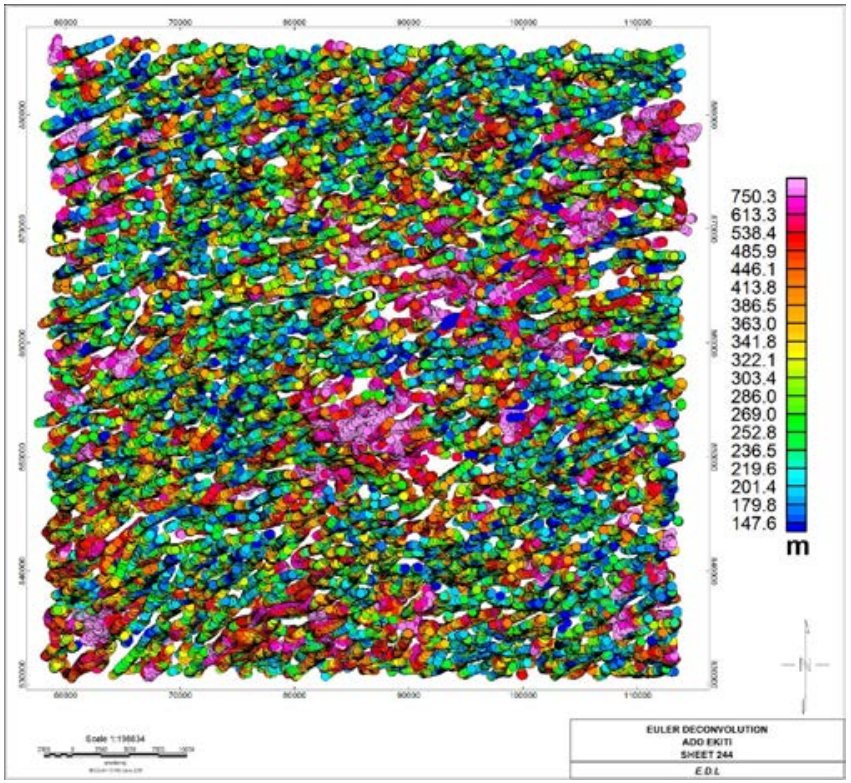

Figure 11. Standard Euler solutions of the study area.

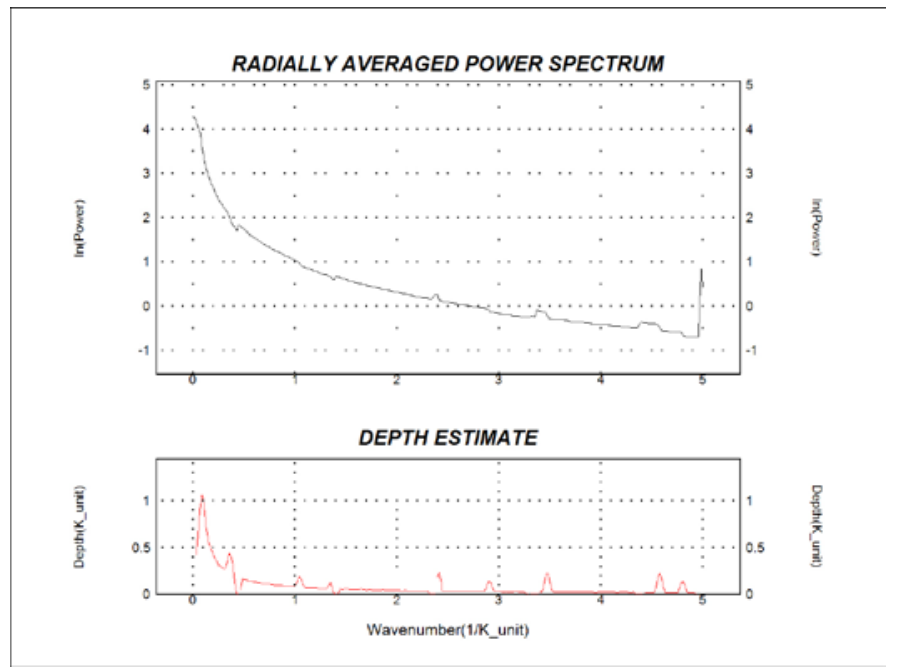

Figure 12. Average power spectrums of aeromagnetic anomaly map indicating gradients used in calculating the average depth to the top of magnetic sources.

\subsubsection{Werner Deconvolution}

Fig.13 shows the Werner deconvolution function which uses the horizontal and vertical derivatives in the calculation of depth to basement of the magnetic anomaly. It assumes the source bodies are either dikes or contacts with infinite depth extent and uses a least-squares approach to solve for the source body (Ku \& Sharp, 1983). Two depth source models (Dike and Contacts model) were assumed and their depths to basement were estimated using the Werner deconvolution function. The Dike model fits the description of depth in the study area. 


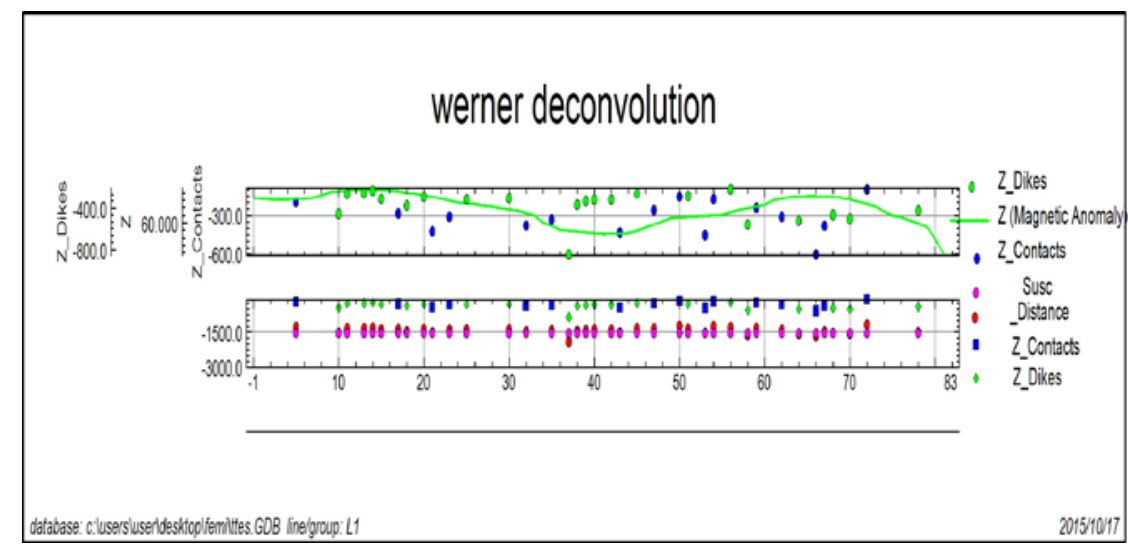

Figure 13. Werner deconvolution of the study area

The lineaments (faults) are marked in black ticks while folds and shearing as interpreted by Graham et al (2014) are marked in arched curves. The orientation and length of the lineament extracted from the Vectorization map (Fig. 14) are demonstrated in a rose diagram to analyze the spatial distribution of lineaments and in attempt to add to the understanding of the directions of the structural control of the study area. The rose diagram (Fig. 15) gives trends: NE-SW, NNE-SSW, and NW-SE with minor ENE-WSW, E-W directions. Out of the 105 extracted lineaments, 70\% (representing the largest) trends in the NNE-SSW direction with $15 \%$ striking in the EW direction. $15 \%$ also strikes in the northwest southeast (NW-SE) and another $6 \%$ trending in the north-south (N-S) direction (Table 1). Most of these trends agreed with previous work carried out in the Benue Trough and parts of the Precambrian basement complex of Nigeria by Ajakaiye et al (1991). According to Dobrin and Savit (1988), lineation in the magnetic contours usually follows regional geology (e.g., intrusive bodies or large faults' strikes) and is thus valuable in lineaments mapping. They also stated that well-defined boundaries between zones having appreciably different degrees of magnetic relief often indicate the presence of major basement faults and fractures.

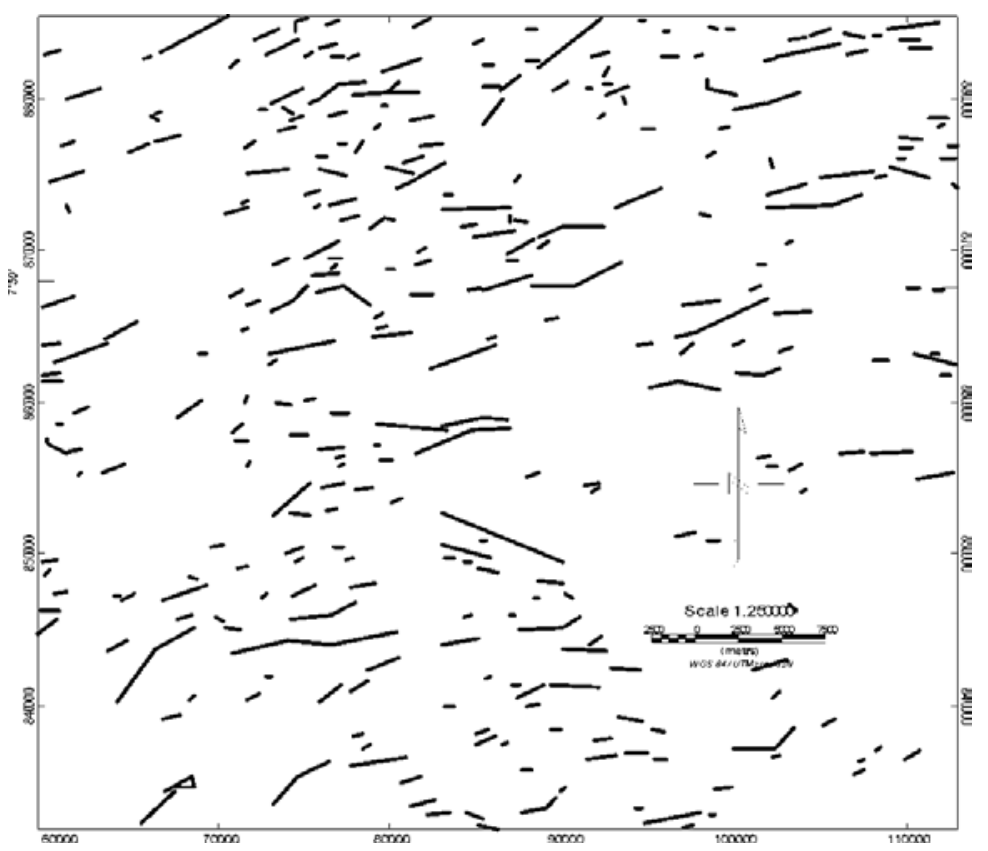

Figure 14. The Lineament/geological structural control and lithologic deformations in the Precambrian basement complex of Ado-Ekiti Southwest and its environs. The portions marked as lineaments and arched structures are of dark straight and angled strokes, representing low magnetic intensities. 


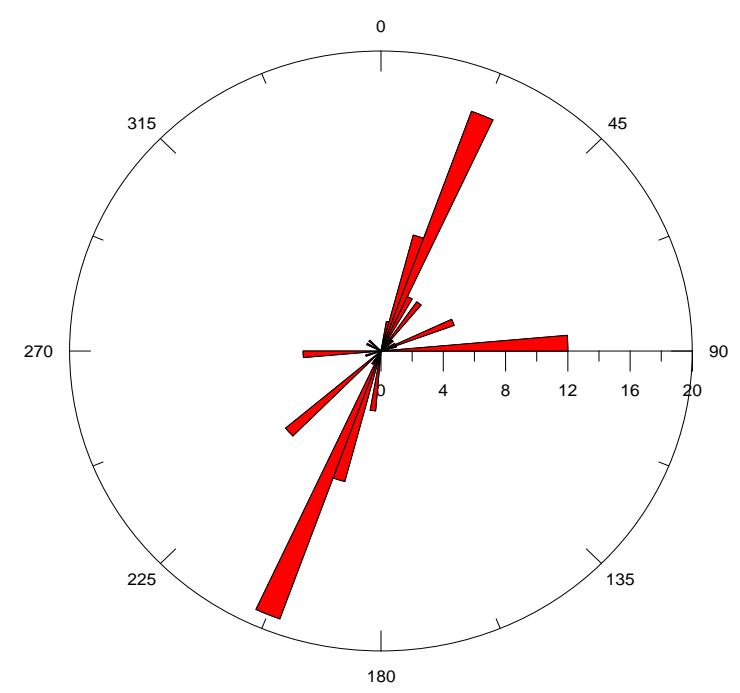

Figure 15. Rose diagram showing the structural trends of Ado-Ekiti region.

Table 1. Distribution and orientation of the structural trend and their accompanied orogeny.

\begin{tabular}{lll}
\hline Lineaments & Trends & Orogeny \\
\hline 70 & NE-SW & Pan- African \\
15 & NW-SE & Kibaran \\
15 & E-W & Liberian \\
\hline
\end{tabular}

\subsection{Upward Continuation}

Figures 16 shows the RTP (grid) continued upward to $100 \mathrm{~m}$ and $800 \mathrm{~m}$. The anomaly patterns identified in this map are a qualitative representation of spatial variation in the magnetic properties of deep basement rocks and structures in the area. For proper understanding of the basement complex, structural analysis must be taken into consideration (Alexander et al., 1998), hence, we need to further process the enhanced Residual Magnetic Intensity map of the study. The RMI was upwardly continued to $100 \mathrm{~m}$ and $800 \mathrm{~m}$ to accentuate the response from the basement rocks. The most important effect of this filter on the map is that, it makes the map smoother and more regional thereby reflecting regional basement anomalies. Not much change was observed at $100 \mathrm{~m}$ upward continuation but the $800 \mathrm{~m}$ result was more pronounced. In Figure 16, the high magnetic intensity of amplitude $100.7 \mathrm{nT}$ to 142.4 nT (AM) still appears as a large sub-rounded anomaly in the central part of the map and extends faintly to the southwestern region of the UC map while the negative anomaly of intensity (AG) $27.5 \mathrm{nT}$ to -156.1 nT still appears very large in the north-central part extending east of the map. The negative anomaly lies in the area underlain by migmatite rocks within the study. This appears to be unusual and it is therefore inferred that the negative anomalies must have resulted from the intrusion of hydrothermal fluids which can deposit less magnetic materials in the fractured rock. The fracture trends northeast-southwest in line with other fractures (lineaments) observed in this area while the positive anomaly in the center of the map rocks extends towards the southwest. The different rock boundaries cannot be discriminately mapped out by the upward continuity filter because the same rock unit exhibits both positive and negative magnetic anomalies thus making it difficult to mark out boundaries of different rock units.

\subsection{Tilt Derivative}

To determine structures (fault and folds), the contacts and edges or boundaries of magnetic sources, and to enhance both weak and strong magnetic anomalies of the area, the tilt derivative filter was applied to both the TMI and the RTP grid. The tilt angle derivative filter attempts to place an anomaly directly 
over its source. Verduzco et al. (2004) showed in their work that tilt derivative filter performs an automatic-gain-control (AGC) filter which tends to equalize the response from both weak and strong anomalies, hence, providing an effective way to trace out along striking anomalies. Tilt angle derivative (TDR) of RMI locates the edges of formations, especially at shallow depths by using the theory that the zero contours are the edges of the formation (Salem et al., 2007). It was observed that the zero contours estimate the location of abrupt changes in magnetic susceptibility values. The zero contour lines in this grid (Fig. 17b) are represented by a yellow colour. RTP brittle deformations are faults and folds while ductile are oval shape as seen in Figure 17b. The structural trends and episode in the study are: Liberian > 2500ma D1 E-W, Pan African orogeny is $650 \pm 150$ ma D3 NE-SW and NW-SE -herald the emplacement of granitoid bodies which establish heat into the country rock and have a structural trend that is curvilinear showing FI (Odeyemi, 1981). Rose diagram lineament map (Fig.15) shows Eburnean $2200 \pm 100$ ma (Birrimean supra crustal) that is deep seated and has experienced notable subsidence thereby creating a basin for deposition of sediments believed to be Eburnean. (Rahaman et. al., 1981). Figure 17a displays most structural features of the area such as the faults, contacts and to some extent the shape of some lithology. Applying the filter on the RTP grid gives a clear picture of the magnetic body and structures in the area as compared to the filter applied on the RMI grid (comparing Fig. 16a and Fig. 16b). The TDR image (Fig. 17a \& 17b) shows different lineaments and contacts in the area. Most of the lithological contacts in the area were delineated from the Fig. 17b (TDR on RTP image). The tilt derivative in Figure $17 \mathrm{a}$ and Figure 17b, amplifies lineaments, which are structural deformations that are related to faults, joints, and arched zones or even geological contacts. The vectorization of Fig. 14 aligns with the tilt derivative map of the study area. Magnetic minerals are mainly concentrated along or aligned with some structures or sedimentary features such as faults or channels.

\subsection{Pseudo-Gravity}

In order to locate and outline crustal magnetic sources, transformation techniques must be applied. A pseudo-gravity transformation is useful in interpreting magnetic anomalies, not because a mass distribution actually corresponds to the magnetic distribution beneath the magnetic survey but because gravity anomalies are in some ways more instructive and easier to interpret and quantify than magnetic anomalies (Blakely, 1995). The pseudo-gravity map (Fig. 18) helps deduce a large causative body trending NE-SW with a density of about $0.103 \mathrm{~g} / \mathrm{cc}$ in susceptibility as seen on the map.

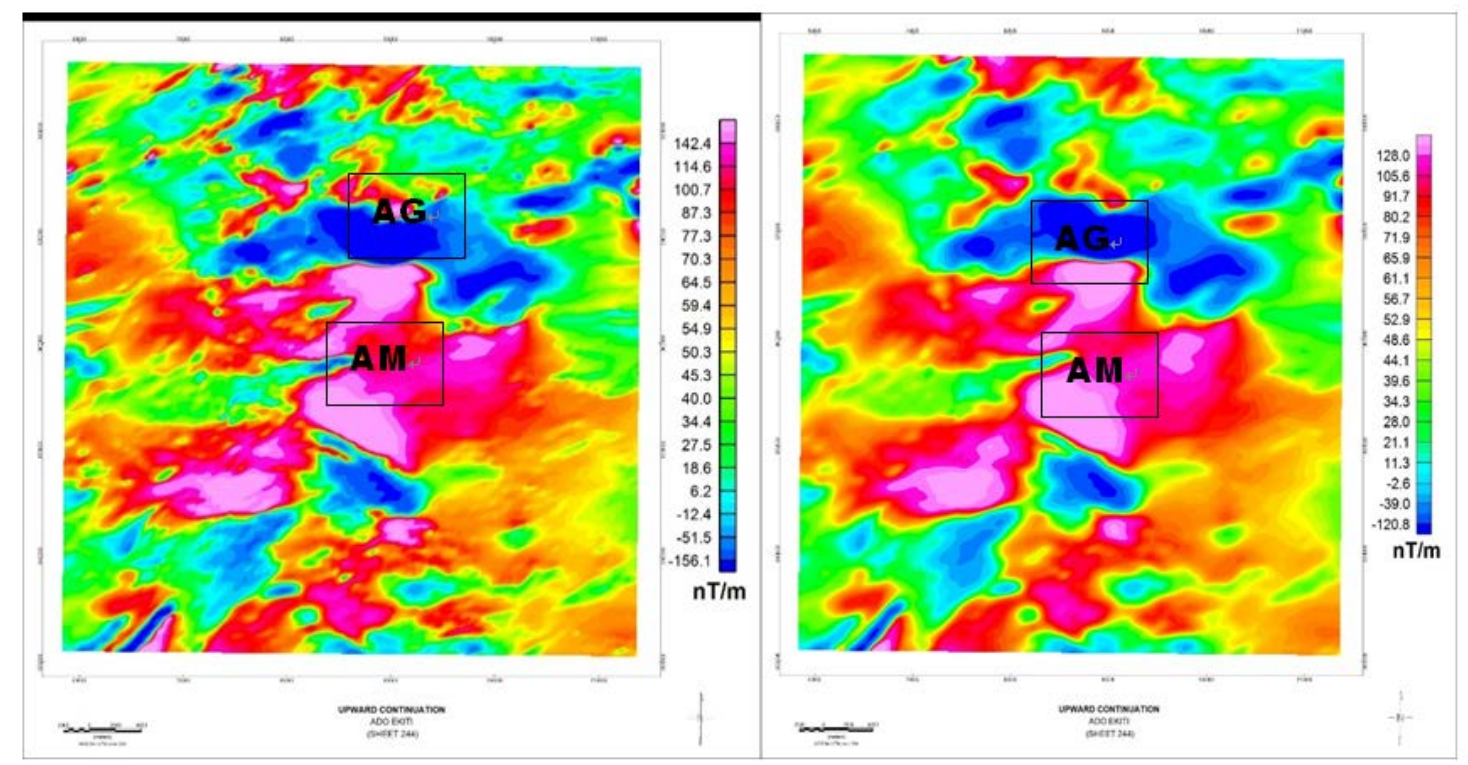

Figure 16. (a-b) RMI (grid) been continued upward to $100 \mathrm{~m}$ and $800 \mathrm{~m}$ 


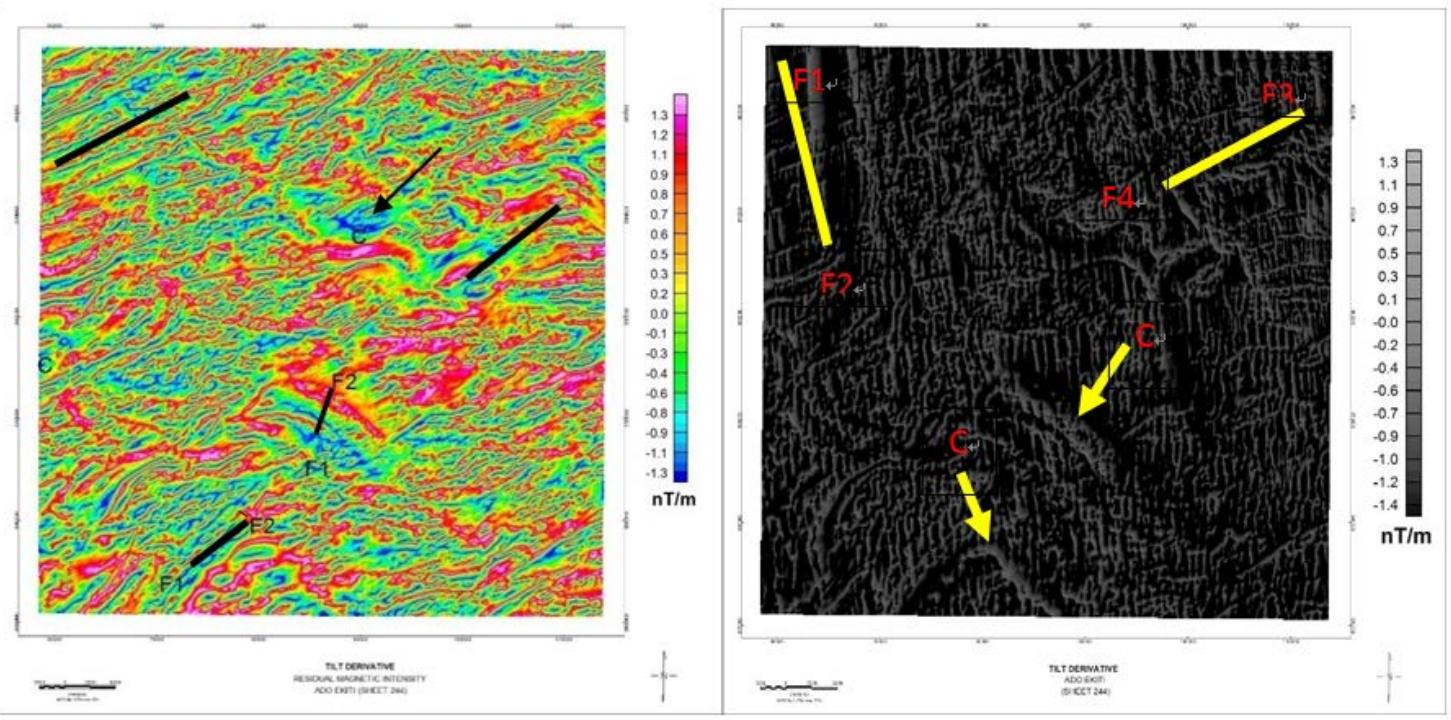

Figure 17: Tilt angle derivative, TDR (a) TDR derived from RMI image (b) TDR derived from RTP displayed in grey scale.

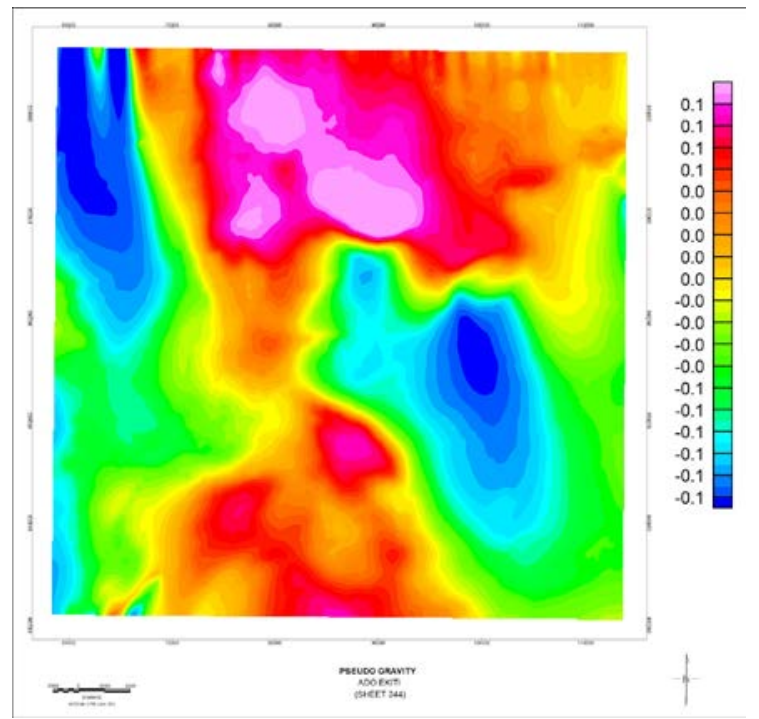

Figure 18. Psuedo-gravity map derived from the RMI Image.

\section{Conclusions}

In order to map out the lithology and geological structures of the study area, aeromagnetic datasets collected over the area were processed and enhanced. The magnetic image enhancing filters applied to the residual magnetic intensity (TMI) are reduction to the pole (RTP), analytic signal, first vertical derivative (1VD), first horizontal derivative, Tilt derivative (TDR) and upward continuation (UC), Downward continuation (DC), Pseudo gravity, Power spectrum and Euler and Werner deconvolutions using Geosoft Oasis Montaj package. These filters helped define the lithological boundaries, intersection of geological structures, faults, folds and contacts. The tilt derivative proved very useful in the delineation of lineaments which were in the form of contacts, faults, folds and joint derivative map. The depth to basement of the formations within the study area was determined using the contact model and the dike models. The contact model produced shallow depth while the dike model on the other hand produced depth for the basement rock. The dike model seems to best fit the study area. This is because 
dike model anomaly occurs at a greater depth than the contact model (Mushayandebvu et al., 2001). Power spectrum was equally used to calculate depth to basement. The aeromagnetic dataset proved valuable in the delineation of most of the lithologies and structures in the area and estimating the depth to basement of the magnetic body proving to be a valuable tool for mapping basement architecture.

Acknowledgment. The authors are grateful to NGSA for the release of the Aeromagnetic dataset of Ado-Ekiti region.

\section{Reference}

1. D.E. Ajakaiye, D.H. Hall, J.A. Ashieka, and E.E. Udensi., Magnetic Anomalies in the Nigerian Continental Mass based on Aeromagnetic Surveys, in P. Wasilewski and P. Hood (Eds.), Magnetic Anomalies-Land and Sea: Tectonophysics, ,192, p.211-230, 1991.

2. M. Aldana, V. Costanzo-Alvarez, and M. Diaz., Magnetic and mineralogic studies to characterize oil reservoirs in Venezuela. Leading Edge, 22 (6), p.526, 2003.

3. M. Alexander, J.C. Pratsch, and P. Corine., Under the Northern Gulf Basin: Basement Depths and Trends: Abstract, Society of Exploration Geophysicists Sixty-Eight Annual Meeting, New. Orleans, LA, 1998, p.45-49.

4. K. Allek, and M. Hamoudi., Regional-scale aeromagnetic survey of south-west of Algeria: a tool for area selection for diamond exploration. J.Afri. earth Sci. 50, p.67-78, 2008.

5. A.Y.B. Anifowose, Remote sensing analysis of Ifewara-Zungeru Megalinear in Nigeria. PhD thesis, Federal University of Technology, Akure, Nigeria, 2004, 169p.

6. R.J. Blakely, Potential Theory in Gravity and Magnetic Applications: Cambridge University Press, Cambridge, 1995, p.441.

7. I.C. Briggs, "Machine Contouring Using Minimum Curvature," Geophysics, 1974, 39, p.39-48.

8. M. B. Dobrin, Introduction To Geophysical Prospecting, $2^{\text {nd }}$ Edition, 1960.

9. M.B. Dobrin, and C. Savit., Introduction to Geophysical Prospecting. 1988: McGraw-Hill, NY, p.867.

10. C. A. Finn, T. W. Sisson, and M. Deszcz-Pan., Aerogeophysical measurements of collapse-prone hydrothermally altered zones at Mount Rainier Volcano: Nature,2001, 409,p. 600-603.

11. C. Foss, Magnetic data Enhancement and Depth Estimation. (H. Gupta, Ed.) Encyclopedia of Earth Sciences Series, 2011, p.736-746.

12. N.K. Grant, Structural distinction between a metasedimentary cover and an underlying basement in the $600 \mathrm{~m} . \mathrm{y}$. old Pan African domain of Northwestern Nigeria, West Africa. Geological Society of American Bulletin, 1978, 89, p.50-58.

13. K.M. Graham, K. Preko, D.D. Wemegah, and D. Boamah., Geological and Structural Interpretation of part of the Buem Formation, Ghana, Using Aerogeophysical Data: Journal of Environment and Earth Science, 4(4), p. 17-31, 2014.

14. F. S. Grant, "Aeromagnetics, geology and ore environments, igneous, sedimentary and metamorphic rocks: an overview," Geoexploration, 23(3), p.303-333, 1985.

15. P. Gunn, D. Maidment, and P.Milligan., Interpreting aeromagnetic data in areas of limited outcrop. AGSO Journal of Australian Geology 83 Geophysics, 17(2), p.175-185, 1997.

16. P. Kearey, M. Brooks, and I. Hill., An Introduction to Geophysical Exploration:2002, Blackwell Publishing, 3rd edn. p.255.

17. C. Ku, and J. Sharp., Werner deconvolution for automated magnetic interpretation and its refinement using Marquart's inverse modeling. Geophysics, 48(6), p.754-774, 1983.

18. X. Li, Magnetic reduction-to-the-pole at low latitudes. Fugro Gravity and Magnetic Services. Houston, USA.:Fugro, 2008.

19. Y. Luo, D.J. Xue, and M. Wang., Reduction to the Pole at the Geomagnetic Equator. Chinese Journal of Geophysics, 53(6), p.1082-1089. 2010.

20. H. Miller, and V. Singh., Potential field tilt-a new concept for location of potential field sources. Journal of Applied Geophysics, 32, p.213-217, 1994,.

21. P. Milligan, and P. Gunn., Enhancement and presentation of airborne geophysical data. AGSO Journal of Australian Geology \& Geophysics, 17(2), p.63-75, 1997. 
22. M. Mushayandebvu, P. van Drielz, A, Reid, and J. Fairhead., Magnetic source parameters of two-dimensional structures using extended Euler deconvolution. Geophysics, 66(3), p.814-823, 2001.

23. T. Ndougsa-Mbarga, A.N.S. Feumoe, E. Manguelle-Dicoum, and J.D. Fairhead., Aeromagnetic Data Interpretation to Locate Buried Faults in South-East Cameroon: Geophysical Society of Finland, Helsinki, 2011, p.63.

24. I. Odeyemi, A Review of the Orogenic Events in the Precambrian Basement of Nigeria, West Africa: Geologische Rundschau, 1981, 70, p.897-909.

25. C.T. Okonkwo, Structural geology of basement rocks of Jebba area, Nigeria. Journal of Mining and Geology, 35(1), p.9-21, 1992.

26. C.C. Okpoli, and F.B. Eyitoyo, Aeromagnetic study of Okitipupa region, Southwestern Nigeria. International Basic and Applied Research Journal, 2(7), p. 1-20, 2016.

27. C.C. Okpoli, and A. Adedibu ., Reconstruction and appraisal of Akunu-akoko iron ore deposits using geological and magnetic approaches, RMZ-M\&G, 63(1) ,pp 19-38, 2016.

28. Omotoyinbo., Geology of Ado-Ekiti. Unpublished BSc project, Ondo State University Ado- Ekiti, 1994.

29. B. Oruc, and H. Selim, H., Interpretation of magnetic data in the Sinop area of Mid Black Sea, Turkey, using tilt derivative, Euler deconvolution, and discrete wavelet transform. Journal of Applied Geophysics, 74, p.194-204, 2011.

30. Porwal, A., E.J.M. Carranza, and M Hale., Tectonostratigraphy and base-metal mineralization controls, Aravali province (western India): new interpretations from geophysical data analysis. Ore geo.Rev. 29 (3-4), 287306, 2006.

31. M.A. Rahaman, Review of the basement geology of South-Western Nigeria. In: Kogbe CA (ed) Geology of Nigeria, 2nd edn, Elizabethan Publishers, Lagos, p.41-58, 1976.

32. M.A.Rahaman and O. Ocan . On relationships in the Precambrian Migmatite-gneisses of Nigeria. Nigeria J Min Geol, 5:23-32, 1978.

33. M.A. Rahaman, Recent advances in the study of the basement complex of Nigeria. Abstract, 1st Symposium on the Precambrian Geology of Nigeria, 1981.

34. M. A. Rahaman, Recent advances in the study of the basement complex of Nigeria. In: Geological Survey of Nigeria (ed) Precambrian Geol Nigeria, , p.11-43, 1988.

35. C. V. Reeves, "The Kalahari Desert, central southern Africa: A case history of regional gravity and magnetic exploration," in The Utility of Gravity and Magnetic Surveys, Society of Exploration Geophysicists, Special Volume, W. J. Hinze, Ed., 1985, p.144-156.

36. C. V., Reeves, Aeromagnetic Surveys Principles, Practice and Interpretation. 2005.

37. W. R. Roest, J. Verhoef, and M.Pilkington., Magnetic interpretation using the 3-D analytic signal. Geophysics, 57 p.116-125, 1992.

38. E.M. Schetselaar and J.J. Rhyan., Remote predictive mapping of the Boothia mainland area, Nunavut, Canada: an iterative approach using landsat ETM, aeromagnetic and geological field data. Can. J. Remote Sens. 35, p.S72-S94, 2009.

39. Silva, A., Pires, A., A. Mccafferty.,R. De Moraes , and H. Xia., Application of Airborne Geophysical Data to Mineral Exploration in the Uneven Exposed Terrains of the Rio Das Velhas Greenstone Belt. Revista Brasileira de Geociências, 33, p.17-28, 2003.

40. D. V. Smith, and D. Pratt., Advanced processing and interpretation of the high resolution aeromagnetic survey data over the Central Edwards Aquifer, Texas: Proceedings from the Symposium on the Application of Geophysics to Engineering and Environmental Problems, Environmental and Engineering Society, 2003.

41. A. Spector, and F. Grant., Statistical Models for Interpreting Aeromagnetic Data: Geophysics, 35, p.293-302, 1970.

42. W.M. Telford, L.P. Geldart, and R.E. Sheriff., Applied Geophysics: 1990, Cambridge University Press, $2^{\text {nd }}$ Ed.

43. G. N. Tsokas, and C.B. Papazachos., Two-dimensional inversion filters in magnetic prospecting: Application to the exploration for buried antiquities: Geophysics, 57, p.1004-1013, 1992.

44. B. Verduzco, J. Fairhead., C. Green,., and C. Mackenzie., New insights into magnetic derivatives for structural mapping. The Leading Edge, 2004, 23, p.116-119.

45. D.T. Thompson, "EULDPH - A new technique for making computer - assisted depth estimates from magnetic data", Geophysics, 47, p.31-37, 1982. 